UDC 1/14:37.01:168

Satenik KUZANYAN

\title{
PHILOSOPHY OF EDUCATION AND ARGUMENTATION
}

\begin{abstract}
This paper presents the basic issues of Philosophy of Education that have been under concern throughout the history, stressing the Janus-faced nature of philosophy of education. Discussing the role, urgency and necessity of argumentation in philosophy of education, the paper presents the understanding of argumentation according to the viewpoint of Yerevan School of Argumentation. It offers the investigation of the argumentation language, its conceptual apparatus in philosophy of education and the study of the components' functioning specificities.
\end{abstract}

Keywords: philosophy of education, Janus-faced nature, "Socratic method" of questioning, reasoning, search for reasons, argumentation, homo argumenticus, logic, language of argumentation.

Introduction

Philosophy of education is a philosophical reflection on the nature, aims, and problems of education. The Philosophy of Education is considered to be Janus-faced, and the reason for that is that it looks both inward to the parent discipline of philosophy and outward to educational practice. Because of its dual focus philosophy of education deals with both sides of the traditional divide between theory and practice, so its subject matters are both basic philosophical issues and more specific issues arising from educational practice. The practical issues arising from the educational practice have implications for a variety of long-standing philosophical problems in epistemology, metaphysics, ethics, and political philosophy (Siegel, "Philosophy of Education"; see also Noddings, 2016).

It is known that the Western philosophical tradition began in Ancient Greece from which, consequently, as a derivate began philosophy of education. Long before, there were professional philosophers of education, philosophers and educators debated questions familiar to contemporary studies in that field. The philosophical views of education were developed by the major historical figures and were reflected in their different theories, particularly in metaphysical, epistemological, ethical, and political ones. By the introduction of Socrates's "Socratic method" of questioning began the tradition according to which reasoning and the search for reasons, due to which can be justified beliefs, judgments, and actions, was and will always remain fundamental, he also insisted that self-knowledge is basic to all knowledge and that education should encourage in everyone the pursuit of the life of reason. Most of the major figures in the history of philosophy of education have been sharing this view of the central place of reason in education, despite other substantial 
differences in their philosophical views (Siegel, "Philosophy of Education"; see also Noddings, 2016).

Socrates' student Plato endorsed this view and assumed that the fundamental task of education is to help students to value reason and to be reasonable, which for him involved valuing wisdom above everything. In his dialogue Republic he set out a vision of providing different sorts of education for different groups of students, depending on their abilities, interests, and stations in life. His utopian vision was considered to be a precursor of what was later called educational "sorting”. Millennia later, John Dewey argued that education should be tailored to the individual child rejecting Plato's hierarchical sorting of students into categories. Plato's student Aristotle also took the highest aim of education to be the fostering of good judgment or wisdom, but he was more optimistic than Plato about the ability of the typical student to achieve it, he also emphasized the fostering of moral virtue and the development of character that reflected in contemporary interest in "virtue theory" in ethics and "communitarianism" in political philosophy (Siegel, "Philosophy of Education", see also Noddings, 2016, pp. 711).

Jean-Jacques Rousseau argued that education should enable the "natural" and "free" development of children. This view eventually led to the modern movement known as "open education". These ideas are in some ways reflected in 20th-century "progressivism," a movement often associated with Dewey. Raising issues concerning gender and its place in education, Rousseau also prescribed fundamentally distinct educations for boys and girls. Giving central place in education to the role of experience, Dewey held that experience is genuinely educational only when it leads to "growth," though this idea has proved to be a problematic and controversial one. Dewey is usually seen as a proponent of "childcantered" education. He emphasizes the importance of student's own interests in determining appropriate educational activities that in modern terms can be called self-consciousness and motivation. For Dewey education is of central importance for the health of democratic social and political institutions, and he developed his educational and political views from a foundation of systematic metaphysics and epistemology (Siegel, "Philosophy of Education").

The history of philosophy of education includes many more figures than Socrates, Plato, Aristotle, Rousseau, and Dewey, in particular, such outstanding philosophers as Thomas Aquinas, Augustine, Thomas Hobbes, René Descartes, John Locke, David Hume, Immanuel Kant, John Stuart Mill, Karl Marx, Bertrand Russell, etc., but unfortunately within the frames of this work it is not possible to refer to them one by one. It is important to stress the fact that despite many differences in their viewpoints concerning the issues of philosophy of education, all these figures took the fundamental aim of education to be the fostering of rationality.

The separation of philosophy of education and the tendency of its formation as a unique branch of philosophical thought can be dated form the second half of XX century. It was influenced by the general tendency of the development of philosophical thought and the possibility and necessity to find constructive solutions to the current issues of education (see Avetisyan, 2007). 
The basic philosophical problems and tasks that have been considered and discussed throughout the history of the subject are the issues concerning:

- the aims of education;

- clarification of educational concepts;

- rights, power, and authority;

- critical thinking or indoctrination;

- the individual and society;

- educational approach to morality;

- teaching, learning, and curriculum;

- educational research.

The most basic problem of philosophy of education is that concerning its aims. Many aims have been proposed by philosophers and other educational theorists that include the cultivation of curiosity and disposition to inquire; fostering of creativity; production of knowledge and of knowledgeable students; enhancement of understanding; promotion of moral thinking, feeling, and action; enlargement of imagination; fostering of growth, development, and self-realization; fulfillment of potential; cultivation of "liberally educated" persons; overcoming close-mindedness; development of sound judgment; maximization of freedom, happiness, or self-esteem; fostering of feelings of community, social solidarity, citizenship, and civic-mindedness; production of good citizens; "civilizing" of students; fostering of ideological purity; cultivation of political awareness and action; fostering of skills and dispositions constitutive of rationality or critical thinking, etc. (Siegel, "Philosophy of Education"). From this perspective, many schools and educational institutions, following their own priorities concerning the aims of education, have special policies and specific orientation on this or that issue, particularly on religious, military, civil, political or other ones.
Both contemporary and historical philosophers of education referred in their works to the issues concerning the aim of education, defending a particular conception or criticizing the conceptions of others. The great range of aims leads to the necessity of appealing to other areas of philosophy, to other disciplines and to educational practice as well. Unfortunately the contemporary discussions of educational policy rarely address the matter (Siegel, "Philosophy of Education").

One of the tasks of the philosophy of education is the clarification of concepts, particularly of key educational concepts, including both the concept of education itself, and related concepts (teaching, learning, schooling, child rearing, indoctrination, etc.) from the point of view of the identification of not only the particular meanings of the concepts, but also their alternative meanings, rendering of explicit ambiguities, revelation of hidden metaphysical, normative, or cultural assumptions, illumination of the consequences of alternative interpretations, exploration of the semantic connections between related concepts, etc. (Siegel, "Philosophy of Education").

There are also a number of issues of philosophy of education concerning the rights of students, parents, teachers; power and authority of institutions and organizations that are being faced during everyday activity and life referring to completely different spheres of education starting from curriculum details and composition, its obligatory or mandatory character, up to the problems of discrimination and injustice. Though these issues are mainly studied by ethics and political philosophy, they also need attention from metaphysics, philosophy of science, psychology, and other areas of philosophy, social science, and law. 
Many educators and educational scholars have championed the educational aim of critical thinking. It has emerged as a major aim of today's education all over the world. Responding to the question "What critical thinking is?" philosophers of education have developed accounts of critical thinking attempting to state what it is and why it is valuable or why educational systems should give the central place to critical thinking cultivating it in students. These accounts generally agree that critical thinkers share at least the following two characteristics: (1) they are able to reason well; (2) they are disposed or inclined to be guided by reasons so evaluated -i.e., actually to believe, judge, and act in accordance with the results of such reasoned evaluations. But beyond this level of agreement lie a range of contentious issues: one cluster of issues is epistemological in nature and the other concerns, whether the skills, abilities, and dispositions constitutive of critical thinking are general or subject-specific (Siegel, "Philosophy of Education"; see also Noddings, 2016).

The question of indoctrination is also under the concern of philosophers of education, particularly from the point whether and how education differs from indoctrination. The theorists are divided into two main camps concerning this issue. One of them assumes that both education and indoctrination are distinct and that indoctrination is undesirable, but others have argued that there is no difference in principle and that indoctrination is not intrinsically bad.

Indoctrination generally is defined in terms of aim, method, or doctrine, so it's either: (1) any form of teaching aimed at getting students to adopt beliefs independent of the evidential support those beliefs may have (or lack); (2) any form of teaching based on methods that instill beliefs in students in such a way that they are unwilling or unable to question or evaluate those beliefs independently; (3) any form of teaching that causes students to embrace a specific set of beliefs -e.g., a certain political ideology or a religious doctrine. According to these characteristics of indoctrination, there can be faced a "confrontation" between critical thinking and indoctrination (Siegel, "Philosophy of Education").

The roots of a number of interrelated problems and issues also start from the society - individual interrelation. All that interrelated problems and issues are conditioned by the question: Should the education serve for the needs of the individual, or for that of the society?

Philosphy of education deals with the problems of moral education as well, or in other words, the educational approach to morality. The question is whether education should strive to instill particular moral beliefs and values in students, or it should aim to enhance students' ability to think through moral issues for themselves. The question is that moral beliefs and values are in some sense relative to culture or community; therefore, attempts to teach morality at least presuppose an indefensible moral absolutism and may even constitute a kind of moral "imperialism" (Siegel, "Philosophy of Education"). This is especially problematic, when the education process takes place in a multinational and multicultural society when the moral values of the representatives of one nation contradict to those of the representatives of other nations.

A number of problems of educational practice starting from the issues concerning teaching, learning, and curriculum raise many 
philosophical issues. The philosophers of education discuss such questions that mainly deal with the choice of the subjects and constitution of their knowledge; the choice of a common curriculum for all students, or differentiation of subjects for different students, depending on their needs and interests; the organization of less-able students education vocational or non-vocational; students' grouping depending on their age, abilities, gender, race, culture, socioeconomic status, etc.; the way how students should be taught and referred to; the necessity of any sort of grading or evaluation; and the questions concerning the aims of particular curriculum areas.

A large amount of research in education that drives much educational policy and practice is being published every year. But educational research raises also many philosophical issues that are largely philosophical, involving philosophy of science (both natural and social) and epistemology. The questions raised by the philosophy of education concerning educational research refer to the way and methods of its realization, interpretation and translation of its results' into policy, revelation of the possible differences of the competent research in the social and natural sciences, the possibility of educational research to be objective, producing objective results (Siegel, "Philosophy of Education").

One answer to these issues and their sensible objections is that every society must answer them, not once and for all time but as well and conscientiously as it can for the benefit of its people and the future of the earth (Noddings, 2016, p. 1).
On the Urgency and Necessity of

Argumentation from the

Viewpoint of Philosophy of Education

In the process of investigation and search for the answers to the aforementioned and many other issues and problems with which the philosophers of education deal with; in their attempts to state, defend their ideas, points of view and convince others to assume and share them, argumentation plays very significant role and is of central importance.

As the founder of Yerevan School of Argumentation academician Georg Brutian states in the third chapter" of his book "Logic, Language, and Argumentation in Projection of Philosophical Knowledge": "argumentation is a kind of reasoning which means a kind of discursive of logical thought where the arguer tries to realise his main aim by means of logical, psychological, rhetorical, axiological, and other component, that is, he tries to convince the recipient to become a coparticipant of the realisation of his project" (Brutian, 1998, p. 90).

Brutian claims "Homo Sapiens is homo argumenticus". He explains this claim firs from the perspective, that "argumentation has a

The chapter is entitled "Argumentation". In the chapter are presented Brutian's reflections and research results on the following issues: 1 . The Architectonic of Argumentation, 2. An Explication of the Main Concepts of Argumentation, 3. Logic of Argumentation, 4. The Language of Argumentation, 5. The Problem of Translatability in Argumentation, 6. Philosophical argumentation, which are presented under corresponding titles in the chapter. In this paper are mainly presented Brutian's approach to the issues on the architectonic of argumentation and the language of argumentation. 
universal character", and second - that "there can be different interpretations of argumentation, but argumentation itself is the same for all people and differs only according to peoples' intellectual or logical abilities". He also specifies that though the argumentation has universal character, it is not absolutely the same in each sphere of peoples' intellectual contacts and it can be modified under the influence of the main characteristics of any particular field in which the argumentation takes place (Brutian, 1998, p. 90).

Brutian formulates the abstract scheme of argumentation as follows "... we argue when we formulate a proposition (the thesis of argumentation), consider all the necessary arguments for and against the thesis, demonstrate the truth of the thesis and the falseness of the antithesis, value the thesis as being the most acceptable among the other true propositions, convince the recipient of all our decisions with the intention of making him think in a similar manner in order to be able to participate in the realisation of the aim of argumentation" (Brutian, 1998, p. 90). He draws parallels between the difference of this argumentation model, its real process and the difference between language and speech.

Referring to the role of logic in argumentation Brutian stresses its importance and centrality. Explaining the viewpoint of the experts, who neglect the role of logic in argumentation by the reduction of all kinds of logic to symbolic logic, based on artificial language, he states that "Argumentation is universal mode of reasoning and logic is, in principle, one of the main components of argumentation, its very essence. The kind of logic we use, logic of common, natural language or logic of artificial language, formal or informal logic, formalised or contentual, etc. or the combination of two or more kinds of logic depends on the concrete field, sphere of application of argumentation" (Brutian, 1998, p. 91). Brutian insists on the statement that "valid and effective argumentation presupposes the alliance of logic and rhetoric" (Brutian, 1998, p. 92), that is contradicting to the view of other experts in the field of argumentation, according to the viewpoint of which argumentation is a branch of psychology.

Referring to the form of argumentation, differentiating its internal and external forms, Brutian defines its internal form to be a combination of different kinds of influences and the typical external form - a dialogue ${ }^{2}$. He mentions, "the thinkers of the Ancient World were masters of dialogue-conversation, the best representative of which was Socrates" (Brutian, 1998, p. 94). The famous "Socratic method" of questioning - the method of "Socratic dialogue" is wildly used in educational practice. The movement Philosophy for Children that started at the end of the $60 \mathrm{~s}$ of $20^{\text {th }}$ century in USA by the efforts of philosopher Matthew Lipman the founder of the Institute for the Advancement of Philosophy for Children was aimed to teach reasoning and argumentation skills to children. Though the pedagogy of philosophy for children is diverse, many practitioners emphasize the use of a community of inquiry (method that has roots in the works of John Dewey) and the Socratic method of questioning (for more details see

2 Considering dialog as the typical external form of argumentation Brutian means not only the typical formal manifestation of dialog, but also its hidden implicit form that can be reflected in the narrative as well. 
Lipman, 2003; Bleazby, 2013; Hovhannisyan, 2014; Kuzanyan, 2015).

Remarks on the Language of Argumentation in Philosophy of Education

Investigating the language of argumentation Brutian states that the combination of the words "the language of argumentation" expresses different concepts and there should be differentiated at least two main concepts: "the language of argumentation" in a linguistic sense and in a conceptual sense. "Linguistically speaking, "the language of argumentation" includes any word from everyday language combined with the syntactical rules of that language by which we express our thoughts" (Brutian, 1998, p. 109). The investigations on the issues of argumentation and particularly on language of argumentation are also reflected in G. Brutian's other works (Brutian, 1992) and in the works of other representatives of Yerevan School of Argumentation, particularly in the studies of H. H. Hovhannisyan (Hovhannisyan, 2006; 2009), M. Avagyan (Avagyan, 1998), E. Atayan (Atayan, 1998), etc.

The basis of argumentation language, in its linguistic sense, is everyday language with which everyday communication is realized. Everyday language is transformed to the language of argumentation in its linguistic sense, when to the everyday language base are added certain specific language layers - "the argumentative language-layers". As is stated by Brutian, the argumentation language, just as any other language, from the linguistic point of view has its semantics and syntax. (Brutian, 1998, p. 109)

The semantics of argumentation language consists of two sublayers:
- the sum of words characteristic for argumentation,

- the words of rhetorical language ${ }^{3}$ (Brutian, 1998, p. 109-110).

"Language argumentation syntax consists of the rules dealing with the combination of the rhetoric of the words of the rhetorical language from the syntactic structure of everyday language as well as from its style" (Brutian, 1998, p. 110). The syntax of argumentation language can be distinguished from the syntax of other languages according to this factor, other specific features that determine certain features of the syntax of the language of argumentation are foundation, conviction, refutation, etc. (Brutian, 1998, p. 110).

From the linguistic point of view "the language of argumentation" has a nationalistic colouring as it depends on the specificities of the concrete national languages (English, Armenian, Dutch, Russian, etc.) (Brutian, 1998, p. 110). The language in which the argumentative act takes place is very important, as it is constructed according to the grammatical and syntactic rules of the language, taking into consideration the specificities of the language, its vocabulary, etc. ${ }^{4}$

The semantics of the language of argumentation consists of all the concepts which

3 The rhetorical component is considered to be one of the characteristic features of the language of argumentation as it varies in different fields of argumentation.

4 The specificities of the influence of linguocultural environment on thinking mechanisms of children have been investigated by the author in her Linguocultural Environment and the "Philosophizing" Child article (see Kuzanyan, 2015). 
are characteristic for argumentation, particularly:

- the categories of argumentation,

- concepts, typical for an argumentative act,

- concepts, typical for that field of knowledge which the argumentative act is dealing with,

- concepts taken from common sense and necessary for the concrete field of argumentation.

These groups of the concepts can be presented in the form of concentric circles starting from the centre in accordance, but this will be done in a very abstract manner, as sometimes it is particularly difficult or even impossible to define to which circle this or that concept of argumentation language belongs. Referring to the implicit level of the language of argumentation, that is no less valuable from the point of view of understanding the real argumentative act, it is very important to distinguish between the explicit and implicit levels of argumentation language semantics. There are many hidden premises of argumentation which are included in the implicit level of argumentation language and it is necessary to transfer every implicit element into an explicit one in argumentation in order to gain an adequate picture of an argumentative act (Brutian, 1998, p. 110-111).

In the conceptual sense the syntax of argumentation language consists of all possible logical and methodological means with the help of which is realised argumentation on the basis of the semantics of the language of argumentation. The everyday language has its specific syntax which is used during argumentation when it is employed in this or that language. Sometimes in an argumentative act contradictions between linguistic and conceptual syntaxes can be observed, particularly when changing the standard arrangement of words in the sentence to emphasise a particular concept. Though the logical construction of inferences can sometimes be artificial, it is necessary to transform implicit, hidden premises into explicit ones that as was already mentioned is very important in an argumentative act. "Argumentation, in a certain sense is the art of transformation of implicit thought into explicit one. ... there are situations where the power of argumentation is to keep some premises as sub-contextual means and demonstrate them in necessary and suitable cases" (Brutian, 1998, p. 113).

Brutian states "the concepts taken from other spheres of knowledge in their original sense can also be used in other relations with the components of the new theory" (Brutian, 1998, p. 101), so from this perspective can be examined the language of argumentation in philosophy of education, its conceptual apparatus, the specifics of its use and functioning in philosophy of education. The investigation of the aforementioned issues is the subject of the author's main research work and will be presented to the scientific community in her future publications.

\section{REFERENCES}

Atayan, E. R. (1998). P'astarkman lezun (The Language of Argumentation, in Armenian). Yerevan: NAS RA Science.

Avagyan, M. H. (1998). Lezvi tarber gortsar'nut'junnery p'astarkman ynt'acqum (Different Operations of Language during Argumentation, in Armenian). Yerevan: NAS RA Science.

Avetisyan, P. S. (2007). Filosofiya obrazovaniya kak metodologicheskaya os- 
nova formirovaniya edinogo obrazovatel'nogo prostranstva gosudarstv-uchastnikov SNG v usloviyakh globalizatsii (Philosophy of Education as a Methodological Base for the Formation of Joint Educational Platform for the Countries-Participants of CIS in the Context of globalization, in Russian). Herald of the social Sciences, 2, 42-54. Yerevan.

Bleazby, J. (2013). Social Reconstruction Learning: Dualism, Dewey and Philosophy in Schools, Routledge. New York: Routledge.

Brutian, G. A. (1992). Ocherk teorii argumentatsii (Outline of Argumentation Theory, in Russian). Yerevan: NAS RA Publication.

Brutian, G. A. (1998). Logic, Language, and Argumentation in Projection of Philosophical Knowledge. Lisbon: Armenian Library of the Calouste Gulbenkian Foundation.

Hovhannisyan, H. H. (2006). Language of Argumentation. Journal of Applied Electromagnetism (JAE). Institute of Communication and Computer Systems (113-123). Athens-Greece.

Hovhannisyan, H. H. (2009). P'astarkman himnaharcery haj p'ilisop'ajakan mtqi patmut'jan hamateqstum. Girq 2.
P'astarkman er\&anjan dproc (Argumentation Issues in the Context of the History of Armenian Philosophical Thought. Book 2. Yerevan School of Argumentation, in Armenian). Yerevan: International Academy for Philosophy Press.

Hovhannisyan, H. H. (2014). Vagh tariqum p'ilisop'ayakan mtac'oghut'yan zargacman her'ankarnery' hay irakanut'yan mej (The Perspectives of Developing Philosophical Thinking Starting from Early Childhood in Armenian Reality, in Armenian). Wisdom, 3(2), 56-75. doi:10.24234/wisdom.v2i3.93

Kuzanyan, S. K. (2015). Lezvamshakut'ayin mijavayry' \& «pilisopayogh» erexan (Linguocultural Environment and the "Philosophizing" Child, in Armenian). Wisdom, 4(1), 164-170. doi:10.24234/wisdom.v1i4.123

Lipman, M. (2003). Thinking in Education (2nd ed.). Cambridge University Press.

Noddings, N. (2016). Philosophy of Education (4th ed.). Westview Press.

Siegel, H. (n.d.). Philosophy of Education. Retrieved May 14, 2017, from Encyclopedia Britannica: https://www.britannica.com/topic/phi losophy-of-education. 